\title{
PROPUESTA DE VALORACIÓN ZOOGEOGRÁFICA PARA LA EVALUACIÓN DE LOS ESPACIOS RED NATURA 2000 DE LA CAPV. EL EJEMPLO DE GÁRATE-SANTA BÁRBARA (PAÍS VASCO)
}

\author{
Pedro José LOZANO VALENCIA ${ }^{(a)}$ - José Antonio CADIÑANOS AGUIRRE ${ }^{(a)}$ - \\ Iker ETXANO GANDARIASBEITIA ${ }^{(\mathrm{b}))}$ \\ (a) Departamento de Geografía, Prehistoria y Arqueología de la UPV/EHU \\ (b) Departamento de Economía Aplicada I de la UPV/EHU
}

Recibido: 08/04/2011

Devuelto: $12 / 05 / 2011$

Aceptado: 20/06/2011

RESUMEN: El artículo se centra en un método de inventariación y valoración zoogeográfica que se inserta dentro de un proyecto de investigación financiado por el Gobierno Vasco (Departamento de Medio Ambiente y Ordenación Territorial) y por el IHOBE (Sociedad Pública de Gestión Ambiental) en la Comunidad Autónoma del País Vasco (CAPV). El objetivo fundamental es el desarrollo de una herramienta metodológica para la valoración y evaluación socioeconómica y ambiental de los Espacios Red Natura 2000 de la CAPV. Dicho modelo, puesto en marcha en el LIC Gárate-Santa Bárbara, quiere ser aplicado al resto de los espacios protegidos de la CAPV como herramienta de evaluación, ordenación y gestión. Se muestran, de esta manera, los resultados parciales derivados de la valoración zoogeográfica dentro de este espacio.

PALABRAS CLAVE: Gárate-Santa Bárbara, valoración zoogeográfica, CAPV, Lugar de Interés Comunitario (LIC), alcornocales.

\section{ZOOGEOGRAPHICAL ASSESSMENT PROPOSAL FOR EVALUATING NATURA 2000 NETWORK AREAS IN THE AUTONOMOUS COMMUNITY OF THE BASQUE COUNTRY. THE EXAMPLE OF GÁRATE-SANTA BÁRBARA (BASQUE COUNTRY)}

ABSTRACT: This article focuses on a zoogeographic assessment method undertaken within a research project funded by Basque Government and IHOBE (Public Corporation of Environmental Management) in the Basque Country. The main aim is to develop a methodological framework in order to assess the Natura 2000 sites of the Basque Country from both socioeconomic and environmental perspectives. This framework has been tested in GárateSanta Bárbara SCI and it would be applied as planning and management tool in the rest of sites. So results derived from the zoogeographic assessment of the site are displayed in this article. 
KEY WORDS: Gárate-Santa Bárbara, zoogeographic assessment, Basque Country, Site of Community Interest (SCI), cork oak woodland.

\section{INTRODUCCIÓN}

El desarrollo económico experimentado durante el siglo XX ha favorecido la aceleración del deterioro ambiental. La pérdida de una gran cantidad de hábitats y ecosistemas naturales ha desembocado en un alarmante descenso de los niveles de diversidad biológica, cuyos efectos son notorios local y globalmente. Se estima que la actividad humana ha incrementado la tasa de extinción de especies hasta situarla 1.000 veces por encima de la natural (WILSON, 1992). De acuerdo con estudios recientes elaborados por el Programa para el Medio Ambiente de las Naciones Unidas (PNUMA), el 60\% de los ecosistemas mundiales se encuentran en estado degradado o son utilizados de manera insostenible. Asimismo, de confirmarse las previsiones acerca del calentamiento global, entre el 18 y 35\% de las especies podrían desaparecer para 2050. En la Comunidad Autónoma del País Vasco (CAPV) existen un total de 20 especies de flora y fauna en peligro de extinción según el catálogo de Vertebrados Amenazados del País Vasco (BEA, 1999). Además, siguiendo criterios establecidos por la Unión Internacional de Conservación de la Naturaleza (UICN), se estima que 34 especies de vertebrados pueden encontrarse en riesgo de desaparición (calificadas como en peligro crítico, en peligro o vulnerables según las categorías de la UICN).

Ante la progresiva pérdida de biodiversidad se han seguido distintos esquemas de actuación. Mientras en un primer momento se optó por proteger, de forma más o menos estricta, a las especies que peores poblaciones o estado presentaban, en la actualidad hay consenso científico sobre la necesidad de conservar los hábitats que dichas especies ocupan como mejor medida para la conservación de dichos taxones. La preservación de hábitats naturales mediante su declaración como Espacios Naturales Protegidos (en adelante ENP), regulando así los usos y actividades a desarrollar en ellos, parece configurarse como la política de conservación más adecuada puesto que el correcto estado de dichos hábitats redunda en el mantenimiento de poblaciones viables de todas aquellas especies sensibles a la destrucción o reducción de su hábitat.

Asimismo, la política de ENPs también ha ido adquiriendo paulatinamente una visión más integradora en respuesta a otro tipo de necesidades sociales diferentes a las de orden ecológico y ambiental. Al margen de ser sus principales objetivos los ENPs han asumido gradualmente objetivos de carácter socioeconómico en la medida en que se entiende contribuyen a la cohesión territorial y al desarrollo de las comunidades ubicadas en su entorno inme- 
diato. En este sentido los métodos de evaluación aplicados en estos lugares deben responder a una visión transdisciplinar y multidimensional, superando los métodos sectoriales y unidisciplinares.

Precisamente en este contexto se mueve este proyecto cuyo objetivo fue el desarrollar una herramienta metodológica para la valoración y evaluación socioeconómica y ambiental de los espacios Red Natura 2000 de la CAPV. Asimismo, la valoración zoogeográfica, objeto de análisis en este artículo, se inserta en el citado marco metodológico general, que, junto a la fitogeográfica, componen la valoración biogeográfica del proyecto. El artículo empieza por describir el marco legislativo y de regulación de las áreas protegidas en la UE y la CAPV para presentar posteriormente el LIC Gárate-Santa Bárbara, objeto de estudio. El apartado cuarto describe los objetivos, metodología y resultados de la valoración zoogeográfica y el último apartado señala las conclusiones alcanzadas.

\section{MARCO DE LEGISLACIÓN Y REGULACIÓN DE ESPACIOS NATURALES PROTEGIDOS}

En el marco comunitario, el primer hito conservacionista de cierto calado fue la aprobación en 1979 de la Directiva Aves (79/409/CEE), que junto con la Directiva Hábitat (92/43/CEE), de 1992, así como otros documentos como los programas de acción o las estrategias comunitarias, han configurado el corpus jurídico y técnico para la conservación de la naturaleza. Ambas directivas constituyen la base sobre la que se está desarrollando la Red Natura 2000 .

En 1993 la Comunidad Europea se adhirió al Convenio sobre Diversidad Biológica, cuyos orígenes se sitúan en la Cumbre de Río de 1992. Sin embargo, la implementación de medidas articuladas coherentemente bajo una estrategia de conservación común no ha logrado una presencia significativa hasta años recientes. La UE aprobó en 1998 la Estrategia de Biodiversidad y en 2001 los planes de acciones sectoriales en los que la biodiversidad fue integrada horizontalmente. Asimismo, tras la Cumbre de Gotemburgo en 2001, donde se adoptó la Estrategia de Desarrollo Sostenible (EDS) de la UE, la conservación de la biodiversidad ha pasado a formar parte de la agenda política al establecerse el objetivo expreso de "detener la pérdida de biodiversidad para 2010". Para afrontar este reto, en 2006 se puso en marcha el correspondiente Plan de Acción, cuyo horizonte temporal va más allá de 2010 y a través del cual se establecieron diez objetivos prioritarios en cuatro ámbitos de actuación. A nivel mundial, la Evaluación de Ecosistemas del Milenio, elaborada entre 2001 y 2005 bajo el auspicio de Naciones Unidas, ha puesto 
de manifiesto la contribución que realiza la conservación de los ecosistemas a la mejora del bienestar humano.

En la CAPV, la preocupación por la conservación de la naturaleza también ha sido creciente desde la década de 1990. La ley 16/1994 de Conservación de la Naturaleza fue clave en este sentido, pues ha constituido el instrumento legislativo sobre el que se ha creado la red de ENP. Así mismo, la ley 3/98 de Protección del Medio Ambiente incide en la protección de la biodiversidad, al ordenar su "cuidado" y establecer las autoridades competentes. La Estrategia Ambiental Vasca de Desarrollo Sostenible 2002-2020 sitúa la protección de la naturaleza y la biodiversidad como su tercera meta. Para su consecución, el Programa Marco Ambiental 2007-2010 estableció un objetivo estratégico centrado en el mantenimiento de la biodiversidad, en virtud del cual ha adoptado nueve compromisos explícitos y once líneas de actuación. Asimismo, en 2009 se aprobó la Estrategia de Conservación de la Naturaleza 2009-2014, donde se constituyen los objetivos prioritarios de actuación en la materia para los próximos años.

No obstante, el gran reto al que se enfrenta la CAPV en materia de conservación de la naturaleza es la implementación de la Red Natura 2000. Hasta el momento se han declarado 52 Lugares de Importancia Comunitaria (LIC) y 6 Zonas de Especial Protección para Aves (ZEPAS), cuya superficie conjunta alcanza prácticamente 147.000 ha (el 20,3\% de la CAPV). El territorio histórico que mayor aportación realiza es Álava, con más de 80.000 ha, el $26 \%$ de su superficie. Los lugares seleccionados han sido declarados LIC o ZEPA de acuerdo con criterios técnicos y científicos correspondientes a especies y hábitats de interés comunitario. Los LIC han sido designados de acuerdo con los Anexos I (tipos de hábitats) y II (hábitats de especies) de la Directiva Hábitats y las ZEPAS se han declarado de acuerdo con las especificaciones de la Directiva Aves. En la última fase de selección de lugares que conforman la Red Natura 2000, los Estados miembros tienen la obligación de designar los LIC como Zonas Especiales de Conservación (ZEC) en un plazo de 6 años desde la aprobación por la Comisión como LIC. Así, las ZEC junto con las ZEPAS pasarán a formar parte de la Red Natura 2000. La implementación definitiva de la Red Natura 2000 es la principal tarea a desarrollar en un futuro próximo, para lo cual se adquirió el compromiso que para 2010 el 100\% de los espacios incluidos en la Región Biogeográfica Atlántica fueran declarados ZEC y el 30\% de los de la Región Mediterránea.

Sin embargo, en la actualidad son sólo cuatro los lugares que están en tramitación para su designación como ZEC. Además, se encuentran en fase de elaboración los documentos para la misma designación de un total de 31 de los LIC y ZEPA aprobados, entre ellos el que nos ocupa: Gárate-Santa Bár- 
bara. Mediante diferentes órdenes se da inicio al procedimiento para la declaración del LIC como ZEC, tras el cual se establece un periodo de 2 meses para formular alegaciones y sugerencias. Posteriormente se aprueban de forma provisional las medidas de conservación, cuya finalidad es el mantenimiento o restablecimiento en un estado favorable de conservación de los hábitats naturales y las especies. Esta aprobación provisional es sometida de nuevo a un periodo de información pública y audiencia, tras el cual se lleva a cabo la aprobación definitiva como ZEC. La participación pública en el proceso se limita, por tanto, a la formulación de alegaciones, sugerencias y al periodo de información pública.

Las ZEC han de contar con las medidas de conservación necesarias, para lo que se prevé, según el artículo 6 de la Directiva Hábitat, la elaboración y puesta en marcha de "adecuados planes de gestión, específicos a los lugares o integrados en otros planes de desarrollo". Una de las cuestiones más interesantes dentro de las consideraciones para la protección de estos lugares, pasa por el fomento o mantenimiento de determinadas actividades humanas tradicionales, ya que, si bien el objetivo de la Red Natura 2000 es el mantenimiento de la biodiversidad, también tiene presente las exigencias económicas, sociales y culturales, así como las particularidades locales de los lugares asignados. Ello debe reflejarse en las medidas de conservación, o en su caso Planes de Gestión, que además deben considerar la evaluación a la que se ha de someter toda actividad que se ejerza en una ZEC. Se entiende por tanto que los Planes de Gestión de las ZEC deberían adecuar las medidas adoptadas a las actividades humanas sostenibles desarrolladas en estos lugares, así como a la potencialidad de sus impactos socioeconómicos. Es más, trabajos como los realizados por LOZANO (2008) demuestran fehacientemente que determinados usos tradicionales garantizan unos niveles de biodiversidad superiores a los registrados dentro de hábitats naturales menos transformados.

Pero, antes de poner en marcha valoraciones de carácter económico, social, etc., es necesario tener un buen conocimiento y realizar una valoración, lo más exhaustiva posible, de los recursos y valores medioambientales. Al respecto, la primera etapa del proyecto se centró en el inventariado y valoración de las distintas unidades ambientales. Para ello y, a través de la combinación de varias capas de información (geología, suelos, orientaciones, pendientes y vegetación) mediante un SIG (Arc Wiew), se definieron una serie de unidades de síntesis que han sido la base del posterior trabajo de inventariación y valoración. 


\section{PRESENTACIÓN DEL ÁREA DE ESTUDIO}

El LIC Gárate-Santa Bárbara (LIC a secas a partir de ahora) se encuentra situado entre los municipios de Zarautz y Getaria (FIG. 1). Al norte aparece delimitado por una pista que discurre por la parte más elevada de la colina o estribación sobre la que se dispone dicha figura de protección. Al sur, por su parte, aparece perfectamente delimitado por la carretera que partiendo de $\mathrm{Za}$ rautz sube hasta el collado de Meagas. Al este los límites coinciden con una brusca caída del monte (en cuyo borde se sitúa la ermita de Santa Bárbara) hacia la carretera de la costa (N-634) y el mar (zona del puerto pesquero de Zarautz). Por su parte, por el extremo occidental el límite discurre por el monte Garate $(258 \mathrm{~m})$, ligeramente al oeste de su alomada cumbre, ya dentro del municipio de Getaria.

Figura 1. Localización del área de estudio

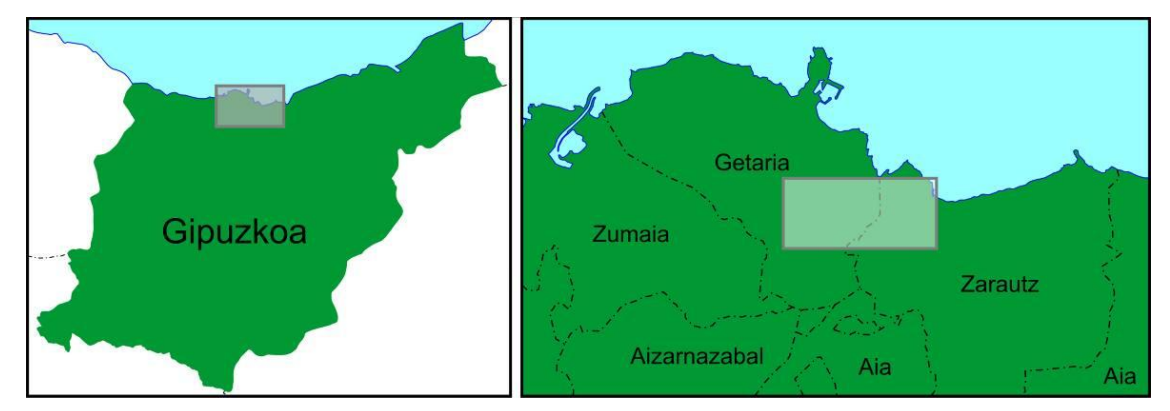

FUENTE: Elaboración propia

Se trata, así pues, de un espacio de unas 142 ha con una serie de características que detallamos a continuación.

En cuanto a la litología, el LIC es bastante homogéneo, porque la mayor parte del mismo, desde la zona más alta, se extiende sobre potentes estratos de areniscas del Eoceno (que posteriormente podrán ser encontrados más al este en las estribaciones de Mendizorrotz, Igeldo, Ulia y Jaizkibel). No obstante, este enclave supone el punto más occidental de esta litología. Dichos paquetes areniscosos presentan alternancias o pasadas de lutitas y microconglomerados. Todas estas litologías son de composición silícea, lo que unido a la fuerte pluviosidad de la zona, condicionan el predominio de suelos ácidos en casi todo el LIC.

Sin embargo, hacia la parte baja de la ladera y cerca de la carretera a Meagas, afloran rocas de edad paleocena. Se tratan, todas ellas, de litologías arcillo-carbonatadas, con alternancia de margas y margocalizas grises en el sector de Meagas, seguidas hacia el sur por una estrecha franja de margoca- 
lizas y margas rosadas. Estas litologías no se descarbonatan por completo al meteorizarse por lo que aportan suficientes carbonatos cálcicos al suelo como para impedir su acidificación por lavado. Todo ello implica un neto cambio en la composición de los suelos y de la vegetación con respecto al resto del LIC.

Estas rocas, depositadas antes de los movimientos alpinos, se plegaron intensamente durante la orogenia alpina hasta dar buzamientos en cuesta, con el talud orientado hacia el norte, hacia el mar Cantábrico. Además de estas estructuras plegadas, también existen importantes fallas con rumbo norte-sur que tienden a cortar perpendicularmente los estratos, de manera que generan importantes discontinuidades.

Geomorfológicamente, las areniscas masivas y la disposición en colina enlongada en sentido este-oeste, ha dado lugar a una amplia ladera, orientada fundamentalmente hacia el sur, de pendiente sostenida y relativamente homogénea que oscila entre el 30 y el $50 \%$, hasta llegar al fondo del valle, ocupado por la autopista A8. Los procesos que más están condicionando el relieve son los derivados de la acción del agua (arroyada fundamentalmente, ligeramente encajada en algunos barrancos de escaso caudal cuando no discontinuo), aunque también se detectan algunos movimientos de ladera como deslizamientos, solifluxión, pied de vache, etc. Todo ello ha generado una ladera con una pendiente relativamente elevada. No obstante, en el límite oriental del LIC se abren algunos escarpes o cantiles en las areniscas, probablemente de tendencia estructural. En esta zona los suelos son escasos, lo que no es óbice para que arraigue la vegetación, incluso leñosa, con ejemplares o especies de cierto interés por su ubicación rupícola.

Climáticamente la zona aparece encuadrada dentro de una tipología oceánica templada, con unas temperaturas medias en torno a los $14^{\circ} \mathrm{C}$, de inviernos suaves y veranos, como consecuencia de la influencia marina, relativamente frescos. Las precipitaciones oscilan entre los 1550 y $1700 \mathrm{~mm}$ anuales. Por ello, el agua de lluvia, en vez de ser conducida ladera abajo encauzada en arroyos, debido a la porosidad de los suelos es conducida subsuperficialmente entre el suelo y el sustrato. Son muy escasos los puntos de agua que discurren de forma superficial, por lo que la vertiente está poco diseccionada

El sustrato, mayoritariamente areniscoso con cierto grado de tectonización, da lugar a la existencia de pequeños acuíferos, no con la morfología típica de los calcáreos (de tipo kárstico), sino que el agua, en este caso, se almacena en los poros de las areniscas y en las fallas y diaclasas. Aunque la cantidad de agua retenida suele ser escasa y más en este caso, con una unidad hidro- 
gráfica reducida, en zonas más extensas y con sustratos de mayor potencia (Igeldo y Jaizkibel), da lugar a áreas fontinales donde no llega a faltar el flujo de agua incluso con años relativamente secos y en época estival. Por la alta pluviosidad, en el LIC hay pequeños rezumaderos o zonas encharcadizas en varios puntos situados cerca de la zona culminal. A pesar de su escasa dimensión, incrementan notablemente la biodiversidad de la zona ya que determinan y sustentan ecosistemas muy diferentes del entorno, como luego se verá en la vegetación. Por eso, consideramos que debe ponerse todo el interés y los medios para su conservación.

Edáficamente, la gran presencia en el sustrato de las areniscas-lutitas eocenas, implican el predominio en el LIC de los suelos de textura arenosa, fácil drenaje y como consecuencia pobres en elementos nutritivos. Químicamente, se caracterizan por el predominio de sílice y de las arcillas provenientes de la alteración de los feldespatos, micas y arcillas heredadas. Por el contrario, los cationes básicos son escasos lo que implica una capacidad de intercambio catiónico y una fertilidad bajas.

El color de estos suelos sobre areniscas suele variar del pardo-rojizo al ocre amarillento y, cuando son poco profundos y/o predominantemente arenosos, su capacidad de retención de agua es reducida. La vegetación, sobre todo en períodos de sequía estival, puede verse perjudicada por esta limitación, máxime cuando las pendientes son acusadas. Desde el punto de vista de la taxonomía edáfica, estos suelos ácidos sobre areniscas u otros materiales silíceos suelen ser rankers y cambisoles húmicos o dístricos. Normalmente los rankers (también denominados leptosoles dístricos o húmicos) suelen presentar un sólo horizonte, de tipo A úmbrico, muy humífero (humus moder o mor) de color oscuro, pedregoso y situado directamente sobre la roca que apenas está alterada. Dada la falta de carbonatos u otro tipo de rocas básicas, estos suelos son de tendencia ácida, rasgo que se acentúa si, como es el caso, las abundantes precipitaciones tienden a lavar aún más los escasos cationes alcalinos y alcalino-térreos que pudieran frenar la acidificación. También habría que destacar la gran cantidad de materia orgánica en el suelo (lo que también contribuye a acidificar el suelo ya que la materia orgánica resultante de la humificación tiene siempre carácter ácido) y los espesores relativamente reducidos, sobre todo en aquellas partes donde la pendiente es fuerte. En el LIC, hemos detectado este tipo de suelos en la zona de Santa Bárbara, a veces incipientes, en la base de los cantiles de la vertiente oriental.

Otros tipos de suelos del LIC sobre areniscas son los umbrisoles, que suponen un mayor desarrollo que los rankers de los que derivan. Estos suelos suelen mostrar un horizonte húmico potente $\mathrm{y}$, en general, una carga en materia orgánica bastante importante. Este horizonte A úmbrico y oscuro (hu- 
mus mor o moder, rico en materia orgánica poco elaborada) tiene un $\mathrm{pH}$ ácido y un espesor apreciable. Por debajo, y sobre la roca madre, existe un horizonte Bw cámbico. Similares a los anteriores, ácidos con un Bw de alteración, pero con un horizonte superficial menos humífero (A ócrico), son los cambisoles dístricos, bastante frecuentes también en el LIC, pero en zonas más alteradas bien por plantaciones forestales, cultivos, paso de caminos, etc.

Sobre las margocalizas paleocenas de la parte baja de la ladera y de Meagas podemos encontrar otros suelos que oscilan entre los cambisoles calcáricos, si no están descarbonatados del todo, o cambisoles eutricos si, habiendo sufrido una descarbonatación intensa, no obstante no están descalcificados.

Por último, en los rezumaderos de la zona alta de Kastilluzarra y Zingira se han formado puntualmente suelos muy especiales, derivados de los cambisoles dístricos antes mencionados, pero con el horizonte $\mathrm{B}$, y ocasionalmente también el horizonte A, hidromorfos, esto es, conformados por la presencia casi permanente de agua. Este ambiente fuertemente reductor determina unos rasgos físico-químicos y biológicos especiales, como son la reducción y solubilidad del hierro en medio ácido (la acidez se mantiene, ya que la hidromorfía no influye en este parámetro) y una permanente saturación de la fase líquida a costa de la gaseosa, que puede conllevar la asfixia de las raíces. Además se hace denotar por una coloración especial de tonos abigarrados que varían desde el gris al azulado al pardo o rojizo en función del nivel freático y de sus variaciones. En estas condiciones, se forman suelos denominados gleysoles o histosoles (turbas). Por lo que hemos comprobado, en los pequeños prados higrófilos-juncales del LIC se dan los primeros (sin descartar del todo cierta turberización en la zona más húmeda del juncalrezumadero) y, sobre todo, los integrados con los cambisoles ácidos predominantes en el entorno, que podríamos clasificar como cambisoles gleycosúmbricos (pseudogleys).

En cuanto a la vegetación, esta conjunción de sustratos ácidos y orientaciones de solanas mayoritariamente, han propiciado que la vegetación potencial de este sector sea a grandes rasgos el alcornocal cantábrico. El alcornoque (Quercus suber), quercínea de tendencia acidófila, sustituye a la encina en estos sustratos más silíceos, pero no es suficiente este factor para explicar su presencia. Se debe, sobre todo, a que su área de distribución, que enlaza con los alcornocales landeses, llegaba hasta aquí de forma natural. Por ejemplo, por el este, en Vizcaya donde los alcornoques son mucho más raros o incluso de posible origen antrópico, la encina ocupa también las edafologías ácidas, por mucho que en un principio se exagerara su carácter calcícola en 
la región. Pero, ya desde hace años se constató la existencia de encinares acidófilos, a los que, a pesar de sus peculiaridades florísticas respecto de los calcícolas o neutrobasófilos, no se les ha otorgado entidad sinecológica diferenciada de los calcícolas. Pero, en la zona de Zarautz (y más hacia el este), existe otro factor que facilita el reemplazo de la encina por el alcornoque sobre los sustratos ácidos y es el ombroclima. Es sabido que las precipitaciones anuales y las de verano aumentan en el País Vasco no sólo de sur a norte sino de oeste a este (por el efecto masa-barrera de los Pirineos), de manera que la mitad oriental de Guipúzcoa es más lluviosa que su mitad occidental y que Vizcaya. Este puede ser uno de los motivos que explican dicha sustitución, si bien en el LIC el alcornoque nunca se desliga del todo del roble común (Quercus robur) y del marojo o rebollo (Q. pyrenaica), que es el potencial de la solana del alto de Gárate y, ya más hacia el este, de los montes de Jaizkibel. En los alcornocales actuales y pasados del LIC siempre han estado y están presentes estos robles e incluso uno más raro que incluso supone novedad para la zona: Quercus petraea. Buena prueba de todo lo dicho es además que la encina llega de forma natural por el oeste hasta el umbral del LIC, hasta Meagas, sobre los suelos margosos neutros o ligeramente ácidos y alguna, de forma aislada, penetra en su perímetro (encinas del alto entre Gárate y Kastilluzar), aunque sin llegar nunca a formar manchas o rodales continuos en el interior del LIC (CADIÑANOS, LOZANO y QUINTANILLA, in press).

En la zona baja del LIC, en general más húmeda y umbrosa que la alta y media ladera, el alcornocal da paso gradualmente al robledal que sería el bosque original de dicha franja, en cualquiera de sus dos versiones vascocantábricas: la acidófila y la mesófila, con todos los intermedios posibles.

Las comunidades ligadas a la influencia marina -vegetación de acantilados litorales y de arenales costeros- completarían la vegetación potencial de la zona por su límite oriental, pero su relevancia en el paisaje actual es mínima, dada la radical modificación y antropización de este espacio.

Aunque de dimensiones muy reducidas, hemos detectado en el LIC otros dos tipos de vegetación que podríamos tachar de permanentes o de vocación potencial. Empezando por ésta, conviene mencionar siquiera la presencia de un pequeño hayedo en la vaguada de Amoingoa. Su espontaneidad podría ser, no obstante, cuestionada, porque el haya ha sido utilizada como árbol de repoblación hasta la más reciente aclimatación de especies foráneas. A favor de esta posibilidad está lo localizado y reducido de nuestra mancha de haya y su apariencia homogénea con fustes de similar edad. En contra la existencia de un topónimo cercano que se refiere a esta especie, Pagotaldia, cuya etimología podría significar "grupo de hayas", de pago, haya, y taldia, grupo (o 
quizás variante local de tantaidia, monte alto) y que indicaría la presencia de un rodal de hayas desde, al menos, la existencia del topónimo.

En cuanto a las comunidades permanentes, la abundante pluviosidad es también la causa de la aparición, en la cara norte y en la zona culminal, de pequeños rezumaderos y tremedales, clasificados como prados higrófilos y prados-juncales. A veces están acompañados por árboles higrófilos: alisos, abedules, sauces, temblones y fresnos. Varios topónimos locales explicitan igualmente estos rasgos: Iztinga, Urkiola...

No obstante, la secular ocupación de estos espacios y su transformación a manos del ser humano ha dado lugar a una serie de usos del suelo que terminan por configurar un mosaico de distintas unidades con características biológicas y paisajísticas diferenciadas. De hecho, son relativamente escasos aquellos espacios que conservan la vegetación potencial antes reseñada. En el mejor de los casos, los alcornocales u otros tipos de bosques de frondosas subsisten modificados estructuralmente para compatibilizar aprovechamientos variados como pueden ser la saca de madera, de leña, los pastos, etc. De ahí su aspecto a menudo adehesado con árboles o pies trasmochos y densidad abierta. O bien se encuentran en etapas de recuperación después de cortas o incendios o más o menos incontrolados.

Es de destacar el peso que, desde mediados del siglo XX, ha tenido la explotación maderera. De hecho, las parcelas con plantaciones arbóreas de especies de rápido crecimiento son frecuentes en el LIC: pinos, cipreses, roble americano, castaños, robinias...

También son importantes las plantaciones de viñedo para la producción de vino chacolí continuadora de una cierta tradición vitivinícola del caserío en la zona. Otras explotaciones (por ejemplo, el caserío de Kaxuategi) mantienen una producción agropecuaria más tradicional, ganadera u hortofrutícola, que se traduce en la pervivencia de huertas y prados de diente o siega. Pero, es esta una dinámica minoritaria. En estos momentos y, al igual que está ocurriendo en otros sectores del País Vasco atlántico, la producción agropecuaria ligada al caserío ha entrado en crisis, de manera que existen importantes extensiones de territorio abandonadas y ocupadas por el matorral típico en forma de argomal y, en menor medida, espinal, zarzal o brezal (Ver FIGURA 2).

\section{VALORACIÓN ZOOGEOGRÁFICA}

Por su contenido y funcionalidad práctica se consideran los siguientes objetivos operativos: 
Figura 2. Mapa de unidades de síntesis del paisaje

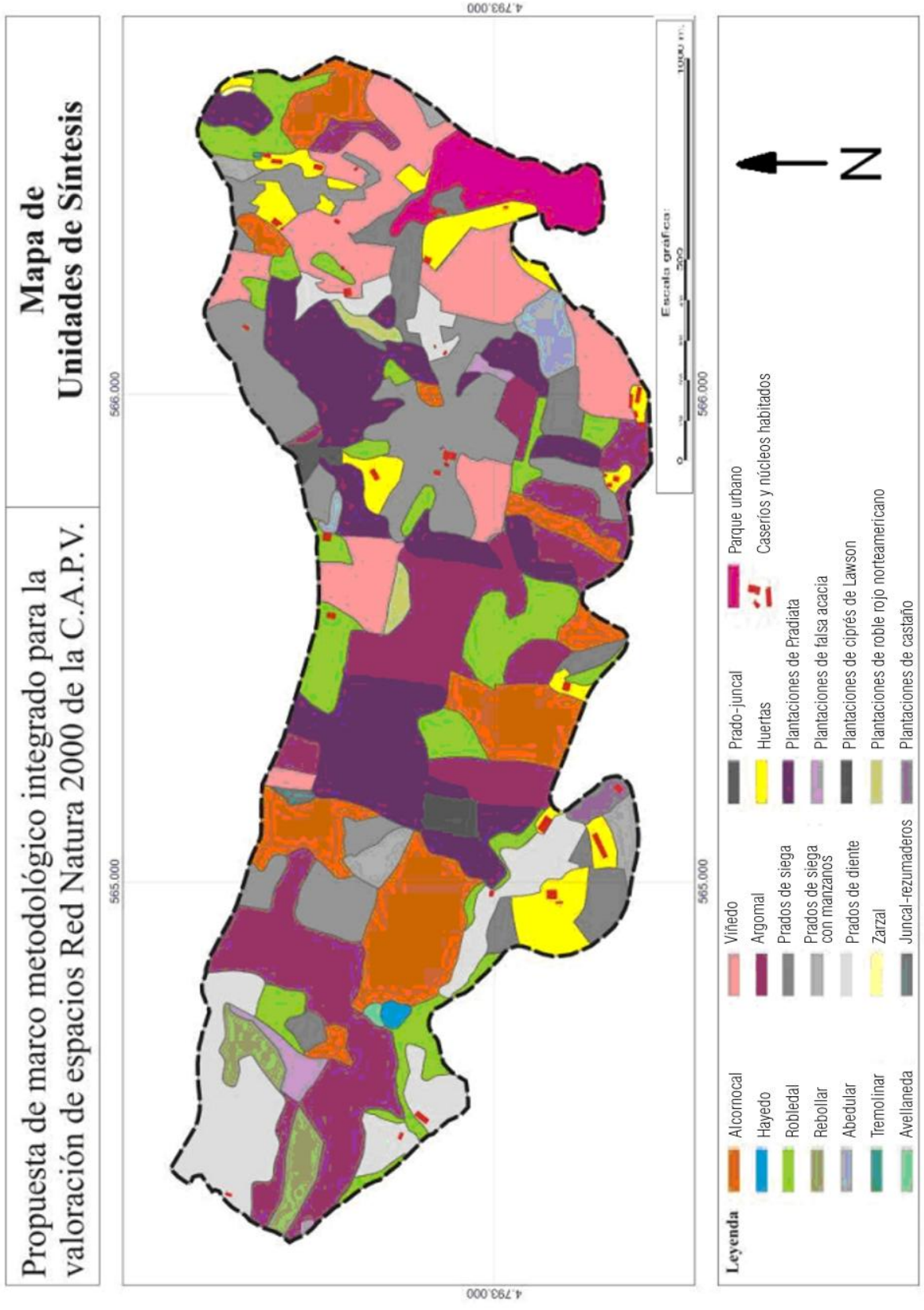

FUENTE: Elaboración propia 
1. Puesta en práctica de un completo método de inventariación zoogeográfica cualitativa y cuantitativa, en la línea de diferentes trabajos y artículos anteriores (LOZANO y MEAZA, 2004a; LOZANO y MEAZA, 2004b; LOZANO et AL., 2004)

2. Creación de protocolos de valoración zoogeográfica que recojan diferentes aspectos como: diversidad específica, diversidad de especies protegidas o amenazas y taxones introducidos.

3. Complementación de valoraciones parciales que puedan ser tenidas en cuenta de forma sectorial atendiendo a los atributos o cuestiones que se consideren oportunas a la hora de planificar y gestionar el espacio donde los aspectos zoogeográficos puedan ser tenidos en cuenta.

4. Generación de un modelo metodológico de inventariación y valoración, lo más sencillo posible, para que pueda ser desarrollado en otros espacios protegidos y por diferentes administraciones: Gobierno Vasco, diputaciones y ayuntamientos.

5. Desarrollo de una completa valoración zoogeográfica para aquellos procesos de planificación (LIC a ZEC), así como para la necesaria formulación de planes de gestión.

6. En definitiva, se trata de contribuir mediante los resultados obtenidos por la valoración zoogeográfica a la elaboración de propuestas concretas para la elaboración/modificación de los planes de gestión del espacio en cuestión.

La valoración de la fauna dentro de un espacio tan pequeño y a la vez tan heterogéneo y con unos usos del suelo relativamente abigarrados no deja de ser una tarea compleja. Es precisamente esta mezcolanza de unidades, con vegetación natural relativamente bien conservada, junto a plantaciones con mayor o menor calidad, espacios forestados y espacios abiertos, ecosistemas relativamente retocados antrópicamente y otros relativamente bien conservados, lo que genera una diversidad de ambientes que, a su vez, se va a plasmar en una diversidad de especies concreta que es lo que se trata de elucidar.

Aunque se hará un breve análisis de lo que supone la carga faunística de este espacio, comparándola con otras realidades territoriales más amplias como Guipúzcoa o el País Vasco, lo cierto es que el análisis, por la propia finalidad y filosofía del proyecto que nos ocupa, se centrará en analizar la mayor o menor riqueza de las distintas unidades sintéticas, en relación a su carga faunística, medida ésta bajo dos variables:

i. Diversidad específica o número de taxones detectados en una determinada unidad.

ii. Calidad de dichos taxones, medida en función de los que se encuentran bajo algún tipo de peligro de desaparición y, por tanto, engloba- 
dos en el Catálogo Vasco de Especies Amenazadas (BEA, 1999). En la posición contraria, aquellas que hayan sido introducidas o muestren un carácter antropófilo estricto, de manera que puedan configurarse como especies plaga. Estas dos últimas casuísticas supondrán una merma cualitativa por su impacto negativo sobre otras especies autóctonas o con un grado de antropofília menos acusado.

La adscripción de una especie a una u otra unidad se ha realizado siguiendo un criterio claro: ese taxón debía estar presente o posado (en el caso de las aves), detectado en canto, detectado en señales o huellas en una determinada unidad.

Para la valoración zoogeográfica del LIC Gárate-Santa Bárbara se han contemplado las siguientes unidades o biotopos extraídos de la valoración fitogeográfica previa:

1. Bosque mixto de frondosas y robledales

2. Alcornocal

3. Hayedo

4. Avellaneda

5. Viñedos

6. Prados de siega

7. Prados y pastos de diente

8. Prados de siega con manzanos

9. Landa-argomal-zarzal

10. Turberas y tremedales

11. Plantaciones de pino insigne

12. Plantaciones de ciprés de Lawson

13. Plantaciones de roble rojo norteamericano

14. Plantaciones de castaño

15. Plantaciones de falsa acacia

16. Parque urbano

17. Huertas y cultivos

18. Caseríos y núcleos habitados

\section{IV.1. Metodología}

A continuación se describen cuáles han sido las herramientas metodológicas empleadas para la toma de datos y la inventariación de los vertebrados sobre el terreno.

\subsubsection{Peces}

La zona no cuenta con una red hidrográfica bien desarrollada, de manera 
que sólo existen pequeños rezumaderos, alguna que otra área fontinal, algún lavadero abandonado, pequeños charcos o, en el mejor de los casos, pequeños arroyos con un carácter totalmente torrencial y un caudal mínimo e intermitente, lo cual genera una ausencia total de fauna ictícola. Aunque se han prospectado todos estos lugares, no se ha detectado ningún taxón.

\subsubsection{Anfibios}

De la misma forma que se ha ido prospectando cada punto de agua para la detección de especies ictícolas, se han tomado en cuenta los diferentes taxones de anfibios. Dicha prospección no sólo se ha centrado en dichos puntos, sino que se han desarrollado las siguientes técnicas:

$\checkmark$ Itinerarios prefijados o transectos.

$\checkmark$ Visitas a lugares sensibles de puesta y análisis e identificación de huevos, larvas y adultos.

$\checkmark$ Escuchas nocturnas.

Además de estas identificaciones directas, se han tomado en cuenta diferentes documentos y sus citas asociadas entre los que habría que destacar:

$\checkmark$ Los documentos, citas y archivos de la AHE (Asociación Española de Herpetología)

$\checkmark$ El atlas y libro rojo de los anfibios y reptiles de España, publicado por el Ministerio de Medio Ambiente y la Asociación Española de Herpetología (PlegueZUELOS, MÁRQUEZ y LIZANA, 2002).

En este caso, el resultado ha sido positivo y se han detectado cinco especies de anfibios.

\subsubsection{Reptiles}

Para el estudio de esta clase se ha atendido a una metodología clásica que aúna dos tipos de herramientas:

$\checkmark$ Transectos.

$\checkmark$ Visitas a zonas sensibles con volteo de piedras, etc.

Además de estas identificaciones directas, se han tomado en cuenta diferentes documentos y sus citas asociadas entre los que habría que destacar:

$\checkmark$ Los documentos, citas y archivos de la AHE (Asociación Española de Herpetología)

$\checkmark$ El atlas y libro rojo de los anfibios y reptiles de España, publicado por el Ministerio de Medio Ambiente y la Asociación Española de Herpetología (PlegueZuelos, MÁrQUEZ y LiZANA, 2002). 
Se han detectado diez taxones de reptiles.

\subsubsection{Aves}

La estacionalidad de esta clase, además de su capacidad de desplazamiento, ha hecho que se consideren todas las épocas del año para su estudio. No sólo se tendrán en cuenta, por tanto, los taxones detectados exclusivamente en época estival o de cría. A nuestro entender, el LIC puede proporcionar recursos, de diferentes tipos, a especies que, aunque no críen en este espacio, lo utilizan. Por esa razón, se tienen en cuenta las distintas aves detectadas sobre cualquiera de los hábitats o biotopos contemplados. Para la detección y estudios de las especies de aves se han utilizado dos métodos básicos:

$\checkmark$ Transectos.

$\checkmark$ Estaciones de escucha.

Además de estas identificaciones directas, se han tomado en cuenta diferentes documentos y sus citas asociadas entre los que habría que destacar:

$\checkmark$ El atlas de las aves nidificantes de Guipúzcoa, realizado por la Sociedad de Ciencias Aranzadi.

$\checkmark$ El atlas de las aves reproductoras de España, publicado por el Ministerio de Medio Ambiente y la Sociedad Española de Ornitología (MARTí y DEL MORAL, 2003).

$\checkmark$ El libro rojo de las aves de España, publicado por el Ministerio de Medio Ambiente y la Sociedad Española de Ornitología (MADROÑO; GONZÁLEZ y ATIENZA, 2004).

$\checkmark$ Las citas, documentos y estudios que obran en poder de la SEO (Sociedad Ornitológica Española).

Como es lógico, este el grupo de vertebrados más abundante en el LIC.

\subsubsection{Mamíferos}

Las herramientas metodológicas para la prospección de esta clase han sido:

$\checkmark$ Análisis de lotes de egragópilas de rapaces nocturnas.

$\checkmark$ Transectos.

$\checkmark$ Citas directas en campo a través de avistamientos.

$\checkmark$ Red de informadores y entrevistas con lugareños, expertos, etc.

$\checkmark$ Visitas a lugares sensibles para los quirópteros: abrigos rocosos, conducciones subterráneas antrópicas, edificios antiguos, etc.

La herramienta básica sobre el terreno, sin duda alguna, ha sido el transecto. No obstante, los mamíferos sufren un recelo hacia la presencia humana 
superior al de cualquier otra clase de vertebrados con lo que la mayor parte de los datos se obtienen a través de la detección e interpretación de huellas; señales de haber comido, pisadas, restos del propio animal, excrementos, etc.

Además de estas identificaciones directas, se han tomado en cuenta diferentes documentos y sus citas asociadas entre los que habría que destacar:

$\checkmark$ Las citas y archivos pertenecientes a la SECEM (Sociedad Española para la Conservación y Estudio de los Mamíferos).

$\checkmark$ El atlas y libro rojo de los mamíferos de España, publicado por el Ministerio de Medio Ambiente (PALOMO, 2007).

$\checkmark$ Para el grupo de los quirópteros se prestó una especial atención a las citas y estudios emanados de la Sociedad Española para la Conservación y el Estudio de los Murciélagos (SECEMU).

Por último, hay que reseñar que existen importantes diferencias entre la extensión de las diferentes unidades. Para evitar el sesgo que esto podía suponer se realizaron todas las técnicas descritas anteriormente de manera homogénea en cada una de las unidades. De esta forma, se han invertido los mismos esfuerzos y los mismos tiempos en cada uno de los hábitats. Esto mitiga, en gran parte, el posible sesgo apuntado.

Se han hallado 28 taxones de mamíferos.

\section{IV.2. Resultados}

Se presentan, a continuación, los resultados obtenidos a través de las técnicas descritas. Queremos, no obstante, advertir que la información que, a continuación se desarrolla, se basa en un estudio cualitativo y que, además, aquellas unidades más extensas, tendrán, lógicamente, mayor posibilidad de contar con un número significativamente superior de especies. En este sentido, unidades como las turberas, las repoblaciones de castaño; falso ciprés; acacia y, por último, los prados con manzanos, son, de menor a mayor, las unidades más reducidas en extensión.

\subsubsection{Valoración por diversidad específica}

Para la mejor presentación de los resultados adjuntamos la siguiente tabla donde aparecen en filas las distintas especies agrupadas según las cuatro clases de vertebrados detectadas sobre la zona. En las columnas, en cambio, se recogen las distintas unidades o biotopos en los que se han detectado. Las "X" muestran la presencia de una determinada especie dentro de esa unidad.

Al mismo tiempo, mediante números se diferencian los taxones de tal forma que, a la cantidad, añadimos la calidad de las especies, medidas en el 
grado de peligro de desaparición según el catálogo vasco de vertebrados amenazados del País Vasco (BEA, 1999):

Sin número: Especies sin ningún tipo de peligro y no incluidas en el catálogo.

$\checkmark$ Señalados con un 1: Especies en peligro, $1^{\mathrm{a}}$ categoría de protección del catálogo. No existe ninguna en la zona.

$\checkmark$ Señalados con un 2: Especies vulnerables, $2^{\text {a }}$ categoría de protección del catálogo.

$\checkmark$ Señalados con un 3: Especies raras, $3^{\mathrm{a}}$ categoría de protección del catálogo.

$\checkmark$ Señalados con un 4: Especies de interés especial, $4^{\mathrm{a}}$ categoría de protección.

$\checkmark$ Señalados con un 5 , aquellas especies que por su carácter antropófilo estricto o por haber sido introducidas, deben tenerse en cuenta, en este caso, para valorar negativamente su presencia por su potencialidad de desplazamiento de taxones autóctonos o la posibilidad de devenir en plagas urbanas.

Tabla 1. Especies de vertebrados por biotopos

\begin{tabular}{|c|c|c|c|c|c|c|c|c|c|c|c|c|c|c|c|c|c|c|}
\hline $\begin{array}{c}\text { Biotopos } \\
\text { Nombre de la especie }\end{array}$ & 1 & 2 & 3 & 4 & 5 & 6 & 7 & 8 & 9 & 10 & 11 & 12 & 13 & 14 & 15 & 16 & 17 & 18 \\
\hline \multicolumn{19}{|l|}{ Anfibios } \\
\hline Salamandra salamandra & $\mathrm{X}$ & $\mathrm{X}$ & & $\begin{array}{l}X \\
X\end{array}$ & & $x$ & & & & $\begin{array}{l}\mathrm{X} \\
\mathrm{X}\end{array}$ & & & & & & & $x$ & \\
\hline Alytes obstetricans & $\mathrm{X}$ & $\mathrm{X}$ & & $\mathrm{X}$ & $\mathrm{X}$ & & & & & $\mathrm{X}$ & & & & & & & $\lambda$ & \\
\hline Bufo bufo & $\mathrm{X}$ & $\mathrm{X}$ & $\mathrm{X}$ & $\mathrm{X}$ & & & & & $\mathrm{X}$ & $\mathrm{X}$ & $\mathrm{X}$ & & $\mathrm{X}$ & $\mathrm{X}$ & $\mathrm{X}$ & $\mathrm{X}$ & & \\
\hline Rana temporaria & $\mathrm{X}$ & $\mathrm{X}$ & $\mathrm{X}$ & $\mathrm{X}$ & & & & & & & $\mathrm{X}$ & $\mathrm{X}$ & & & & & & \\
\hline Subtotal & 4 & 4 & 2 & 5 & 1 & 1 & 0 & 0 & 1 & 4 & 2 & 1 & 1 & 1 & 1 & 1 & 1 & 0 \\
\hline \multicolumn{19}{|l|}{ Reptiles } \\
\hline Lacerta viridis & & & & & & & $\mathrm{X}$ & $\mathrm{X}$ & & & & & & & $\mathrm{X}$ & $\mathrm{X}$ & $\mathrm{X}$ & \\
\hline Lacerta vivipara & & & & & & & & & & $\mathrm{X}$ & & & & & & & & \\
\hline Podarcis hispanica & & $\mathrm{X}$ & & & & & & & $\mathrm{X}$ & & & & & & & & & \\
\hline Podarcis muralis & $\mathrm{X}$ & $\mathrm{X}$ & & & & $\mathrm{X}$ & $\mathrm{X}$ & & $\mathrm{X}$ & & & & & & & $\mathrm{X}$ & $\mathrm{X}$ & $\mathrm{X}$ \\
\hline Anguis fragilis & $\mathrm{X}$ & $\mathrm{X}$ & $\mathrm{X}$ & $\mathrm{X}$ & & $\mathrm{X}$ & $\mathrm{X}$ & $\mathrm{X}$ & $\mathrm{X}$ & & $\mathrm{X}$ & & $\mathrm{X}$ & & & $\mathrm{X}$ & $\mathrm{X}$ & $\mathrm{X}$ \\
\hline Coronella austriaca & & $\mathrm{X}$ & & & & $\mathrm{X}$ & $\mathrm{X}$ & & & & & & & & & $\mathrm{X}$ & & \\
\hline Coronella girondica & & $\mathrm{X}$ & & & & $\mathrm{X}$ & & & $\mathrm{X}$ & & & & & & & & & \\
\hline Elaphe longissima (4) & $\mathrm{X}$ & $\mathrm{X}$ & & $\mathrm{X}$ & & $\mathrm{X}$ & $\mathrm{X}$ & & $\mathrm{X}$ & & $\mathrm{X}$ & & $\mathrm{X}$ & $\mathrm{X}$ & & $\mathrm{X}$ & & \\
\hline Natrix natrix & $\mathrm{X}$ & $\mathrm{X}$ & $\mathrm{X}$ & $\mathrm{X}$ & & $\mathrm{X}$ & $\mathrm{X}$ & $\mathrm{X}$ & $\mathrm{X}$ & $\mathrm{X}$ & $\mathrm{X}$ & $\mathrm{X}$ & $\mathrm{X}$ & $\mathrm{X}$ & $\mathrm{X}$ & $\mathrm{X}$ & $\mathrm{X}$ & $\mathrm{X}$ \\
\hline Vipera seoanei & & $\mathrm{X}$ & & & & $\mathrm{X}$ & $\mathrm{X}$ & & $\mathrm{X}$ & & & & & & & & & \\
\hline Subtotal & 4 & 8 & 2 & 3 & 0 & 7 & 7 & 3 & 7 & 2 & 3 & 1 & 3 & 2 & 2 & 6 & 4 & 3 \\
\hline \multicolumn{19}{|l|}{ Aves } \\
\hline Pernis apivorus (3) & $\mathrm{X}$ & $\mathrm{X}$ & & & & & & & & & & & & & & & & \\
\hline Milvus migrans & $\mathrm{X}$ & $\mathrm{X}$ & & & & & & & & & & & & & & $\mathrm{X}$ & & \\
\hline Circus cyaneus (4) & & & & & & $\mathrm{X}$ & & $\mathrm{X}$ & & & & & & & & & & \\
\hline Accipiter gentilis(3) & & $\mathrm{X}$ & & & & & & & & & & & & & & & & \\
\hline Accipiter nissus (4) & $\mathrm{X}$ & & & $\mathrm{X}$ & & & & & & & $\mathrm{X}$ & & $\mathrm{X}$ & & $\mathrm{X}$ & & & \\
\hline Buteo buteo & $\mathrm{X}$ & $\mathrm{X}$ & $\mathrm{X}$ & & & $\mathrm{X}$ & $\mathrm{X}$ & $\mathrm{X}$ & & & $\mathrm{X}$ & $\mathrm{X}$ & $\mathrm{X}$ & $\mathrm{X}$ & $\mathrm{X}$ & $\mathrm{X}$ & $\mathrm{X}$ & $\mathrm{X}$ \\
\hline Falco tinnunculus & $\mathrm{X}$ & $\mathrm{X}$ & & & & $\mathrm{X}$ & $\mathrm{X}$ & $\mathrm{X}$ & $\mathrm{X}$ & $\mathrm{X}$ & $\mathrm{X}$ & & $\mathrm{X}$ & & & $\mathrm{X}$ & $\mathrm{X}$ & \\
\hline Falco subbuteo(3) & $\mathrm{X}$ & $\mathrm{X}$ & & & & & & & & & $\mathrm{X}$ & & $\mathrm{X}$ & & & $\mathrm{X}$ & & \\
\hline Phasianus colchicus (5) & & & & & & $\mathrm{X}$ & & $\mathrm{X}$ & & & & & & & & & & \\
\hline Coturnix coturnix (5) & & & & & & $\mathrm{X}$ & & & & & & & & & & & $\mathrm{X}$ & \\
\hline Scolopax rusticola & $\mathrm{X}$ & $\mathrm{X}$ & & $\mathrm{X}$ & & & & & $\mathrm{X}$ & & $\mathrm{X}$ & & & & & & & \\
\hline $\begin{array}{l}\text { Columba livia (domestica) (5) } \\
\text { Columba palumbus }\end{array}$ & $\mathrm{X}$ & $\mathrm{X}$ & & & $\mathrm{X}$ & & $\mathrm{X}$ & $\mathrm{X}$ & $\mathrm{X}$ & & & & & & & $\mathrm{X}$ & $\mathrm{X}$ & $\mathrm{X}$ \\
\hline
\end{tabular}




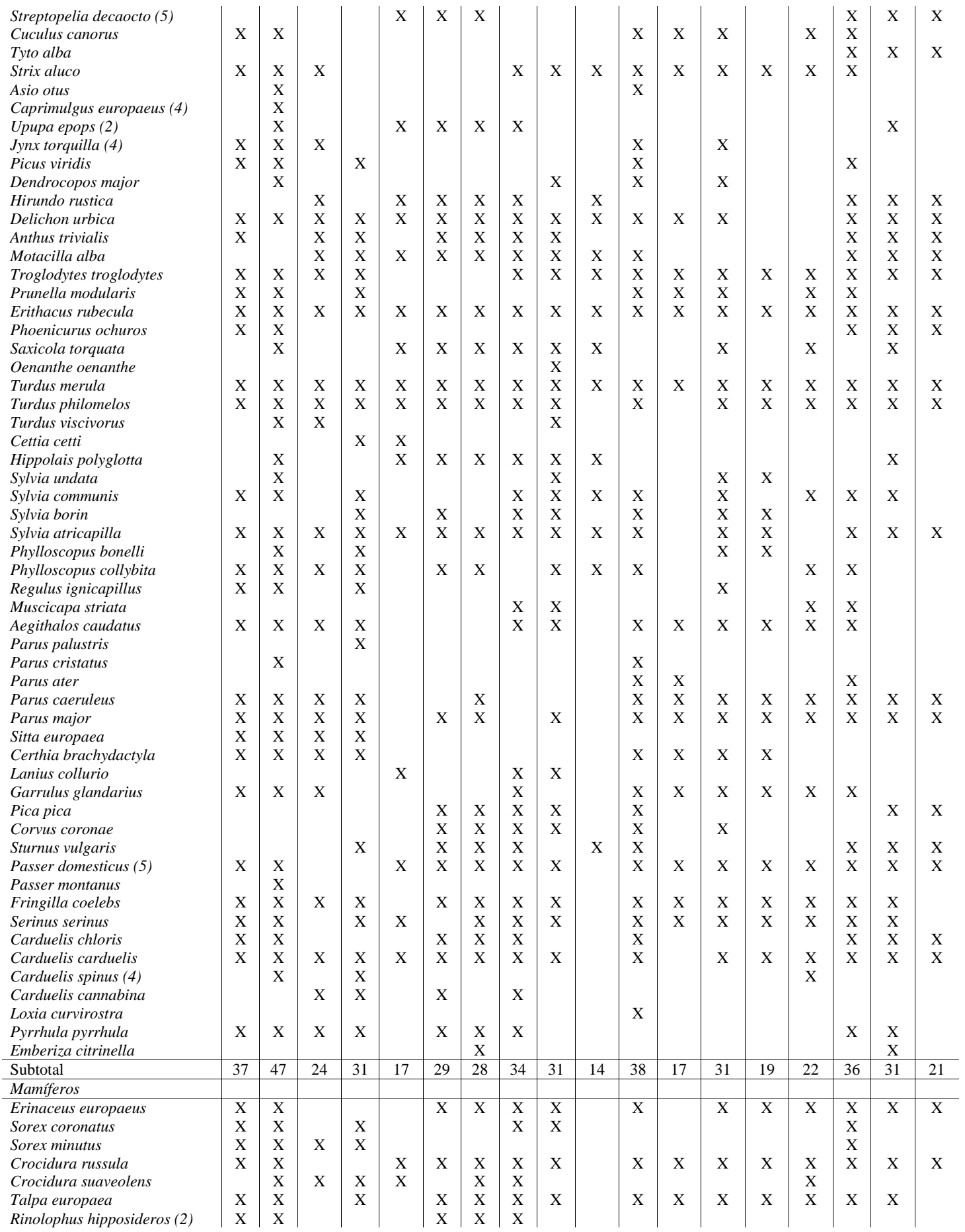


Myotis mystacina

Myotis myotis(3)

Pipistrelus pipistrelus

Plecotus austriacus (4)

Lepus europaeus

Oryctolagus cuniculus

Sciurus vulgaris

Clerhionomys glareolus

Pitymys duodecimcostatus

Microtus agrestis

Apodemus sylvaticus

Ratus norvegicus (5)

Mus domesticus (5)

Glys glys (2)

Vulpes vulpes

Mustela nivalis

Martes foina

Meles meles

Genetta genetta

Sus scrofa

Capreolus capreolus

Subtotal

Total taxones

Puesto jerárquico

En lo que se refiere al número total de taxones con los que cuenta la zona:

$\checkmark 0$ taxones de peces

$\checkmark 5$ taxones de anfibios

$\checkmark 10$ taxones de reptiles

$\checkmark 70$ taxones de aves

$\checkmark 28$ taxones de mamíferos

$\checkmark$ Esto hace un total de 113 taxones

Por su parte, Guipúzcoa contaría con:

$\checkmark 17$ taxones de peces

$\checkmark 13$ taxones de anfibios

$\checkmark 15$ taxones de reptiles

$\checkmark 142$ taxones de aves

$\checkmark 58$ taxones de mamíferos

$\checkmark$ Esto hace un total de 243 taxones

Y la Comunidad Autónoma del País Vasco:

$\checkmark 20$ taxones de peces

$\checkmark 17$ taxones de anfibios

$\checkmark 21$ taxones de reptiles

$\checkmark 179$ taxones de aves

$\checkmark 71$ taxones de mamíferos

$\checkmark$ Esto hace un total de 308 vertebrados 
Todo ello significa que la zona de estudio cuenta con un $0 \%$ de peces, el $38,5 \%$ de los taxones de anfibios con respecto a Guipúzcoa, mientras que, con respecto a la CAPV en su conjunto, serían el 29,4\%. Para los reptiles, la zona cuenta con el 66,7\% de los que existen en Guipúzcoa y el 47,6\% de los existentes en la CAPV. En lo que respecta a las aves, la zona cuenta con el 49,3\% de los presentes en la provincia y el $39,1 \%$ de los existentes o citados para la CAPV. Los mamíferos, por su parte, representan el $48,3 \%$ y $39,4 \%$ respectivamente. En resumen, el 46,5\% de los vertebrados existentes en Guipúzcoa, mientras el 36,7\% de todos los registrados en la CAPV, cifras bastante respetables para un ámbito que supone sólo el 0,07 \% del territorio.

A la vista de la tabla varias son las cuestiones que habría que destacar. En primer lugar, según la diversidad específica por clases y unidades, para los anfibios las unidades que mayor valor tendrían son, por este orden, la avellaneda, el alcornocal, Los bosques mixtos de frondosas y robles y las turberas y tremedales. Por otro lado, no se detectó ningún taxón en tres unidades: pastos de diente, prados de siega con manzanos y núcleos habitados, sin que esto signifique que no existan.

En lo que se refiere a los reptiles, las unidades más ricas en este grupo son el alcornocal, los prados de siega, los pastos de diente, la landa-argomalzarzal y el parque urbano, mientras en el viñedo no se detectó ningún reptil y se detectaron pocos taxones en las repoblaciones de ciprés de Lawson, el hayedo, las turberas y tremedales y las plantaciones de castaño y falsa acacia.

Por su parte, las aves muestran una mayor cantidad de especies dentro de ambientes como el alcornocal, las plantaciones de pinar, el parque urbano, los robledales y bosques mixtos y los prados con manzanos. Las unidades que menor diversidad específica presentan son: las turberas y tremedales disculpables por su pequeña extensión, los viñedos, las repoblaciones de ciprés de Lawson y, por último, las plantaciones de castaño.

En lo que respecta a los mamíferos, las unidades más interesantes serían: el alcornocal, los pastos de diente, los pastos con manzanos o frutales, los robledales y bosques mixtos, la avellaneda, el parque urbano y las zonas de huertas y cultivos. Por su parte, muestran cierta escasez de mamíferos los viñedos, las repoblaciones de falso ciprés, las turberas y tremedales y, por último, las plantaciones de castaño.

Si tomamos en cuenta el cómputo global de taxones de vertebrados por unidades destaca por encima de las demás el alcornocal. Otras unidades con un alto número en taxones pero ya a cierta distancia serían: los robledales y bosques mixtos, el parque urbano, los pinares de repoblación, los prados con 
manzanos o frutales, la avellaneda y los pastos de corta y diente. Por su parte, con bajas cifras en taxones habría que destacar, por este orden: el viñedo, las repoblaciones de ciprés de Lawson, las zonas de turberas, tremedales y rezumaderos y, por último, las plantaciones de castaño.

\subsubsection{Valoración por calidad específica}

\subsubsection{Valoración por diversidad específica protegida}

Tabla 2. Taxones vertebrados en diferentes grados de peligro por unidades o biotopos (Catálogo Vasco de Especies Amenazadas) [1: En Peligro (EP), 2: Vulnerable (V), 3: Rara (R), 4: De Interés Especial (IE)]

Aparece una segunda subtabla donde la primera fila indica los biotopos, la segunda el número de taxones bajo algún grado de protección y la tercera indica los resultados de la fórmula (Valor=5 $\mathrm{x}$ $\mathrm{EP}+4 \times \mathrm{V}+3 \times \mathrm{R}+2 \mathrm{x} \mathrm{IE})$. La cuarta indica el puesto jerárquico según el valor final del citado sumatorio.

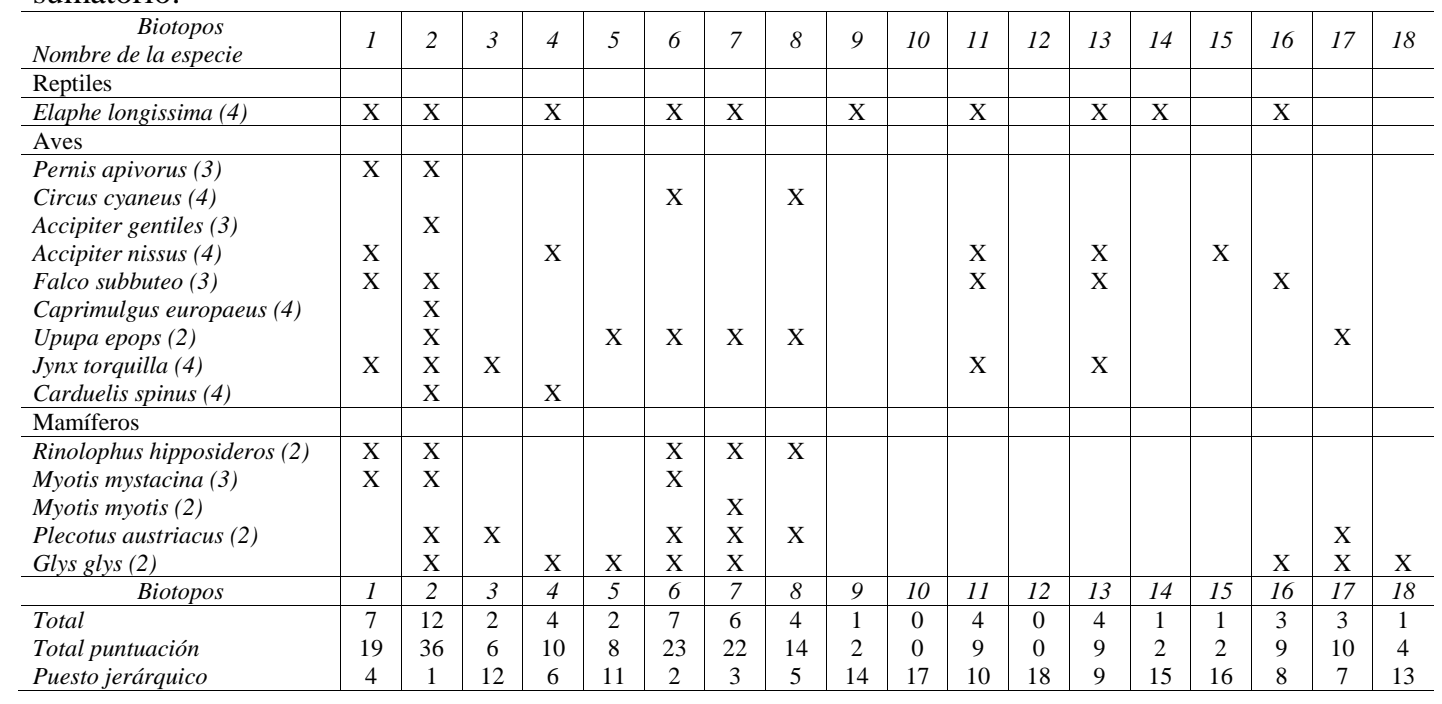

En lo que se refiere a taxones englobados en algunas de las 4 categorías contempladas por la ley 16/1994, de 30 de junio, de conservación de la Naturaleza del País Vasco y su decreto derivado 167/96, de 9 de julio, por el que se regula el Catálogo Vasco de Especies Amenazadas de la Fauna y Flora Silvestre y marina, la zona cuenta con:
$\checkmark 0$ taxones en peligro
$\checkmark 5$ taxones vulnerables
$\checkmark 4$ taxones raros
$\checkmark 6$ taxones de interés especial

Por su parte, Guipúzcoa contaría con: 
$\checkmark 6$ taxones en peligro

$\checkmark 24$ taxones vulnerables

$\checkmark 29$ taxones raros

$\checkmark 42$ taxones de interés especial

Y la Comunidad Autónoma del País Vasco:

$\checkmark 13$ taxones en peligro

$\checkmark 29$ taxones vulnerables

$\checkmark 40$ taxones raros

$\checkmark 63$ taxones de interés especial

Todo ello significa que la zona de estudio cuenta con el $0 \%$ de taxones en peligro, el $20,8 \%$ de los taxones vulnerables, con respecto a Guipúzcoa, mientras que con respecto a la Comunidad Autónoma serían el 17,2\%. Para los taxones raros, la zona cuenta con el 13,8\% de los que existen en Guipúzcoa y el $10 \%$ de los existentes en la CAPV. Por último, cuenta con el 14,3\% de los taxones de interés especial catalogados y existentes en Guipúzcoa, mientras sólo el 9,5\% de todos los registrados en la CAPV.

\subsubsection{Valoración por taxones antropófilos estrictos o introducidos}

Tabla 3. Taxones vertebrados introducidos o antropófilos estrictos. Separadas por una fila aparece una segunda subtabla donde la primera fila indica los biotopos, la segunda el número total de especies introducidas o antropófilas estrictas y la tercera el puesto jerárquico con respecto al número de taxones bajo dicha categoría

\begin{tabular}{|c|c|c|c|c|c|c|c|c|c|c|c|c|c|c|c|c|c|c|}
\hline Nombre de la Especie & 1 & 2 & 3 & 4 & 5 & 6 & 7 & 8 & 9 & 10 & 11 & 12 & 13 & 14 & 15 & 16 & 17 & 18 \\
\hline Aves & & & & & & & & & & & & & & & & & & \\
\hline $\begin{array}{l}\text { Phasianus colchicus } \\
\text { Coturnix coturnix } \\
\text { Columba livia (domestica) } \\
\text { Streptopelia decaocto } \\
\text { Passer domesticus }\end{array}$ & $\mathrm{x}$ & $\mathrm{X}$ & & & $\begin{array}{l}X \\
X \\
X\end{array}$ & $\begin{array}{l}\mathrm{X} \\
\mathrm{X} \\
\mathrm{X} \\
\mathrm{X}\end{array}$ & \begin{tabular}{|l}
$X$ \\
$X$ \\
$X$
\end{tabular} & $\begin{array}{l}x \\
x\end{array}$ & $\mathrm{x}$ & & $\mathrm{X}$ & $\mathrm{X}$ & $\mathrm{X}$ & $\mathrm{X}$ & $\mathrm{X}$ & $\begin{array}{l}X \\
X \\
X\end{array}$ & $\begin{array}{l}X \\
X \\
X \\
X\end{array}$ & $\begin{array}{l}X \\
X \\
X\end{array}$ \\
\hline Mamiferos & & & & & & & & & & & & & & & & & & \\
\hline $\begin{array}{l}\text { Ratus norvegicus } \\
\text { Mus domesticus }\end{array}$ & & & & & & $\mathrm{X}$ & $\mathrm{X}$ & $\mathrm{X}$ & & & $\mathrm{X}$ & & & & & $\begin{array}{l}\mathrm{X} \\
\mathrm{X}\end{array}$ & $\begin{array}{l}X \\
X\end{array}$ & \begin{tabular}{|l|}
$X$ \\
$X$
\end{tabular} \\
\hline Biotopos & 1 & 2 & 3 & 4 & 5 & 6 & 7 & 8 & 9 & 10 & 11 & 12 & 13 & 14 & 15 & 16 & 17 & 18 \\
\hline Total & 2 & 1 & 0 & 0 & 3 & 5 & 4 & 4 & 2 & 0 & 2 & 1 & 1 & 1 & 1 & 5 & 6 & 5 \\
\hline Puesto jerárquico & 9 & 15 & 18 & 16 & 7 & 4 & 5 & 6 & 10 & 17 & 8 & 14 & 13 & 12 & 11 & 3 & 1 & 2 \\
\hline
\end{tabular}

Como se observa, las especies introducidas no son excesivas. En el caso de Gárate-Santa Bárbara puede llamar la atención que, englobados dentro de esta categoría, aparezcan especies como el faisán y la codorniz. Lo cierto es que, de forma natural no existirían, de manera que los ejemplares detectados son los escapados o soltados de granjas y caseríos, así como los introducidos con fines cinegéticos.

Por unidades, las que mayores porcentajes de este tipo de taxones muestran son, por este orden: las huertas, los núcleos habitados y caseríos, el par- 
que urbano, los pastos de siega y los pastos de diente. Por su parte, aquellos biotopos que mejor calidad registran al contar con el menor número de especies introducidas o antropófilas son: el hayedo, las turberas y tremedales, la avellaneda, el alcornocal y las repoblaciones de ciprés de Lawson.

\section{V.3. Valoración total final}

De cara a la valoración final por unidades o biotopos se desarrolla la fórmula que a continuación aparece. Ésta ha sido probada en otros trabajos como LOZANO (2008) dando interesantes resultados y configurándose como una metodología válida y sencilla para este tipo de trabajos e informes.

$\mathrm{VF}=\mathrm{N}^{\mathrm{o}}$ de especies $+(5 \mathrm{x}$ En Peligro $+4 \mathrm{x}$ Vulnerables $+3 \mathrm{x}$ Raras $+2 \mathrm{x}$ De interés especial) - especies introducidas o antropófilas estrictas

$$
\mathrm{VF}=\mathrm{NE}+(5 \times \mathrm{EP}+4 \times \mathrm{V}+3 \times \mathrm{R}+2 \times \mathrm{IE})-\mathrm{EIA}
$$

Tabla 4. Valoración del interés zoogeográfico por unidades o biotopos

\begin{tabular}{l|r|r|r|r|r|r|r|r|r|r|r|r|r|r|r|r|r|r|r}
\hline Total taxones & 61 & 80 & 38 & 53 & 22 & 53 & 53 & 54 & 52 & 25 & 56 & 23 & 46 & 27 & 36 & 57 & 50 & 32 \\
\hline Subtotal taxones & 61 & 80 & 38 & 53 & 22 & 53 & 53 & 54 & 52 & 25 & 56 & 23 & 46 & 27 & 36 & 57 & 50 & 32 \\
\hline Subtotal en peligro & 0 & 0 & 0 & 0 & 0 & 0 & 0 & 0 & 0 & 0 & 0 & 0 & 0 & 0 & 0 & 0 & 0 & 0 \\
\hline Subtotal vulnerables & 4 & 16 & 4 & 4 & 8 & 16 & 20 & 12 & 0 & 0 & 0 & 0 & 0 & 0 & 0 & 4 & 8 & 4 \\
\hline Subtotal raras & 9 & 12 & 0 & 0 & 0 & 3 & 0 & 0 & 0 & 0 & 3 & 0 & 3 & 0 & 0 & 3 & 0 & 0 \\
\hline Subtotal de interés especial & 6 & 8 & 2 & 6 & 0 & 4 & 2 & 2 & 2 & 0 & 6 & 0 & 6 & 2 & 2 & 2 & 2 & 0 \\
\hline Subtotal antropófilas o introd. & -2 & -1 & 0 & 0 & -3 & -5 & -4 & -4 & -2 & 0 & -2 & -1 & -1 & -1 & -1 & -5 & -6 & -5 \\
\hline Total general & 78 & 115 & 44 & 63 & 27 & 71 & 71 & 64 & 52 & 25 & 63 & 22 & 54 & 28 & 37 & 61 & 54 & 31 \\
\hline
\end{tabular}

Como se puede observar a la vista de la TABLA 4, existe una unidad con una puntuación realmente alta y destaca: se trata de los alcornocales. Esta unidad sobrepasa los 100 puntos. En segundo lugar se situaría, con 78 puntos, los robledales y bosques mixtos, en tercer lugar con 71 los prados de diente y siega. Por el contrario, las unidades más pobres en puntuación son, por este orden; las repoblaciones de falso ciprés, las turberas y tremedales, el viñedo y las repoblaciones de castaño.

Son las unidades de bosques autóctonos, por lo tanto, las que mayores puntuaciones reciben, seguidas de unidades bastante disímiles como son los espacios abiertos en forma de prados y pastizales, tanto de diente como de siega. La existencia de espacios muy cercanos donde se combinan estos dos grandes tipos de unidades, junto a otras como los matorrales, enriquecen ostensiblemente en fauna el conjunto. Llama la atención que una unidad con vegetación alóctona como es el pinar (mayoritariamente de Pinus radiata, aunque también se pueden encontrar extensiones mucho más reducidas de Pinus sylvestris), muestre una puntuación relativamente elevada. En este caso, se justifica por la existencia de masas maduras, con fustes que van más allá de los 30 años y con un sotobosque bien desarrollado que muestra unas 
coberturas elevadas, tanto en el estrato subarbustivo como arbustivo y herbáceo.

Sin embargo, otro tipo de repoblaciones como las de falso ciprés o castaño, aparecen como las unidades con menor valor faunístico. En el primero de los casos se debe a lo apretado y sombrío de este tipo de plantación, aún joven y de escasa extensión, un mocultivo donde es imposible que crezcan otras especies que no sean el Chamaecyparys lawsoniana u otros estratos que no sean el arbóreo. Por su parte, las repoblaciones de castaño aparecen también muy escasas en otras especies y estratos, lo cual redunda en una pobreza estructural a todos los niveles. Otras unidades como las turberas o el viñedo reciben también puntuaciones bajas. La falta de diferentes estratos, en el primer caso, como la intensidad de las labores derivadas de la producción vitivinícola en el segundo, pueden explicar, en gran medida, esta pobreza.

Tabla 5. Tabla sintética y jerárquica por unidades o biotopos

\begin{tabular}{l|l|l|l|l|l|l|l|l|l|l|l|l|l|l|l|l|l|l}
\hline Biotopos & 1 & 2 & 3 & 4 & 5 & 6 & 7 & 8 & 9 & 10 & 11 & 12 & 13 & 14 & 15 & 16 & 17 & 18 \\
\hline Subtotal jerarquico taxones & 2 & 1 & 12 & 6 & 18 & 7 & 8 & 5 & 9 & 16 & 4 & 17 & 11 & 15 & 13 & 3 & 10 & 14 \\
\hline Subtotal jerarquico protegidas & 4 & 1 & 12 & 6 & 11 & 2 & 3 & 5 & 14 & 17 & 10 & 18 & 9 & 15 & 16 & 8 & 7 & 13 \\
\hline Subtotal jerarquico antropófilas o introd. & 9 & 15 & 18 & 16 & 7 & 4 & 5 & 6 & 10 & 17 & 8 & 14 & 13 & 12 & 11 & 3 & 1 & 2 \\
\hline Total jerarquico general & 2 & 1 & 12 & 5 & 16 & 4 & 3 & 6 & 11 & 17 & 7 & 18 & 9 & 15 & 13 & 8 & 10 & 14 \\
\hline
\end{tabular}

La TABLA 5 muestra la posición de cada biotopo según la valoración de los criterios de protección, así como la posición o ranking total final de cada uno de los biotopos que queda de la manera siguiente:

1. Alcornocal

2. Bosque mixto de frondosas y robledales

3. Prados y pastos de diente

4. Prados de siega

5. Avellaneda

6. Prados de siega con manzanos

7. Plantaciones de pinos

8. Parque urbano

9. Plantaciones de roble rojo norteamericano

10.Huertas y cultivos

11.Landa-argomal-zarzal

12.Hayedo

13.Plantaciones de falsa acacia

14.Caseríos y núcleos habitados

15.Plantaciones de castaño

16.Viñedos

17.Turberas y tremedales

18.Plantaciones de falso ciprés 


\section{CONCLUSIONES}

La valoración zoogeográfica llevada a cabo pone de manifiesto la importancia de establecer mecanismos de valoración y evaluación in situ en los propios lugares de la Red Natura 2000. La normativa europea en la materia (Directiva Hábitats y Directiva Aves) establece los lugares a designar de acuerdo con los listados de hábitats y especies respondiendo a una visión de arriba abajo (top-down). Sin embargo, para la ordenación y gestión de los lugares parece ineludible establecer una visión de abajo a arriba (bottom-up) como la desarrollada en este artículo. La valoración específica de determinados lugares Natura 2000 contribuirá a establecer las bases para una ordenación y gestión más eficiente y eficaz en la medida en que se adapte a las singularidades y características específicas de cada lugar.

Más en concreto, entendemos que resultados de valoraciones zoogeográficas como la descrita pueden contribuir a la toma de decisiones en el desarrollo de los siguientes aspectos:

$\checkmark$ Medidas para la ordenación y gestión de hábitats específicos para preservar las especies animales más representativas por las que el lugar ha sido considerado espacio Red Natura 2000.

$\checkmark$ Medidas para la preservación de especies animales, en particular para aquellas especies consideradas de "segundo orden" y por el que el lugar específicamente no ha sido considerado Natura 2000.

$\checkmark$ En el marco de los corredores ecológicos, diseño y establecimiento de lugares de paso para la fauna, en particular con respecto a las áreas que circundan el espacio en cuestión.

\section{BIBLIOGRAFÍA}

BeA, A. (1999): Vertebrados amenazados del País Vasco. Eusko JaurlaritzaGobierno Vasco. Vitoria.

Cadiñanos AguirRe, J.A., Lozano, P. y Quintanilla, V. (in press): «Propuesta de marco metodológico integrado para la valoración biogeográfica de espacios Red Natura 2000 de la comunidad autónoma del País Vasco. El ejemplo de Gárate-Santa Bárbara (Guipúzcoa)». Boletín de la AGE, in press.

LOZANO, P.J. y MEAZA, G. (2004a): «Valoración por cuadrículas de los recursos zoogeográficos del sector noreste de la provincia de Guipúzcoa. Ordenación y gestión de los mismos». Boletín de la Asociación de Geógrafos Españoles, 35: 33-54. Madrid.

LoZANO, P.J. y MEAZA, G. (2004b): «Valoración por unidades geosistémicas de los recursos zoogeográficos del sector noreste de la provincia de Guipúzcoa. Ordenación y gestión de los mismos». Ería, 60: 117-129. Oviedo.

LoZANO, P.J.; MEAZA, G. y CADIÑANOS, J.A. (2004): «Bases para el diseño de un Atlas Geográfico de Fauna». En PANADERA, J.M et AL.: Estudios en Biogeogra- 
fía 2004. Libro homenaje a José Manuel Rubio Recio y Jesús García. Aster Editorial. Terrassa: 229-239.

LoZANo, P.J. (2008): Bases para una zoogeografía aplicada. Diseño de una metodología geográfica de Atlas de Fauna. Aplicación a los vertebrados del sector nororiental de Guipúzcoa (País Vasco). Herka editores. Donostia-San Sebastian.

MAdroño, A.; GonZÁleZ, C. y ATIENZA, C. (Eds.) (2004): Libro Rojo de las Aves de España. Ministerio de Medio Ambiente y Sociedad Española de Ornitología. Madrid.

MARTí, R. y DEL MoRAL, J.C. (Eds.) (2003): Atlas de las Aves reproductoras de España. Ministerio de Medio Ambiente y Sociedad Española de Ornitología. Madrid.

Palomo, J.M. (Ed.) (2007): Atlas y Libro Rojo de los Mamíferos Terrestres de España. Ministerio de Medio Ambiente y Sociedad Española para la Conservación de los Mamíferos. Madrid.

Pleguezuelos, J. M.; Márquez, R. y Lizana, M. (Eds.) (2002): Atlas y Libro Rojo de los Anfibios y Reptiles de España. Ministerio de Medio Ambiente y Asociación Española de Herpetología. Madrid.

WiLson, E.O. (1992): La diversidad de la vida. Edición Crítica Drakontos. Barcelona.

\section{ANEXO DE ACRÓNIMOS}

AHE: Asociación Herpetológica Española

CAPV: Comunidad Autónoma del País Vasco

EDS: Estrategia Vasca de Desarrollo Sostenible

EIA: Especies Introducidas o Antropófilas estrictas

ENP: Espacios Naturales Protegidos

EP: Especies En Peligro

IE: Especies de Interés Especial

LIC: Lugar de Interés Comunitario

NE: Número Total de Especies

PNUMA: Programa para el Medio Ambiente de las Naciones Unidas

R: Especies Raras

SECEM: Sociedad Española para la Conservación y Estudio de los Mamíferos

SECEMU: Sociedad Española para la Conservación y el Estudio de los Murciélagos

SEO: Sociedad Ornitológica Española

SIG: Sistema de Información Geográfica

UE: Unión Europea

UICN: Unión Internacional para la Conservación de la Naturaleza

V: Especies Vulnerables

VF: Valoración Final

ZEC: Zonas de Especial Conservación

ZEPAS: Zonas de Especial Conservación para las Aves 